Original Article

Received/Accepted Dates

29.06.2021/28.07.2021

DOI

10.52096/jsrbs.6.1.7.13.24
Journal of Social Research and Behavioral Sciences

Sosyal Araştırmalar ve Davranış Bilimleri Dergisi

ISSN:2149-178X

Volume: 7 Issue: 13 Year: 2021

\title{
Zorunlu Vatandaşık Davranışı ile Presenteeism Arasındaki İlişkinin İncelenmesi
}

Açelya TELLI DANIŞMAZ

Y1ldız Teknik Üniversitesi

Yönetim ve Organizasyon ABD

İşletme Yönetimi Programı

ORCID: 0000-0001-8344-7315

Doç. Dr. Serdar BOZKURT

Yıldız Teknik Üniversitesi

İİBF İşletme Bölümü

ORCID: 0000-0002-4745-9965

Doç. Dr. Yasemin BAL

Y1ldız Teknik Üniversitesi

İIBF İşletme Bölümü

ORCID: 0000-0002-3718-3424

\section{Özet}

Örgütsel vatandaşlık davranışının karşıtı ve karanlık yüzü olarak nitelendirilebilecek zorunlu vatandaşlık davranışı (ZVD), örgütsel davranış ile birlikte organizasyonların son zamanlarda üzerinde durmaya başladığı bir kavram haline gelmiştir. Zira zorunlu vatandaşlık davranışı, çalışan ve organizasyonla ilgili pek çok sonucu yakından ilgilendiren bir kavram olarak karşımıza çıkmaktadır. Farklı fiziksel ve ruhsal sağlik sorunlarına rağmen işe gelmeye devam etmek olarak ifade edilen presenteeism diğer bir deyişle işte var olamamadır. Bu doğrultuda çalışmanın temel amacı, zorunlu vatandaşlık davranışı ile presenteeism arasındaki ilişkinin incelenmesidir. Bu amaçla Türkiye'de çeşitli sektörlerde beyaz yakalı olarak çalışan 374 kişiye çevrimiçi (online) anket şeklinde yöneltilen sorulardan elde edilen veriler SPSS programı aracılığıyla analiz edilmiştir. Analizden elde edilen bulgular neticesinde, zorunlu vatandaşlık davranışları ile presenteeism arasında pozitif yönde orta düzeyde bir ilişki olduğu görülmüsstür.

Anahtar Kelimeler: Örgütsel Vatandaşlık Davranışı, Zorunlu Vatandaşlık Davranışı, Presenteeism. 


\title{
Examinatıon The Relationship Between Compulsory Citizenship Behavior And Presenteeism
}

\begin{abstract}
The concept of compulsory citizenship behavior (CCB), described as the dark side of organizational citizenship behavior, has become a concept that organizations have recently begun to focus on with organizational behavior. Because compulsory citizenship behavior appears as a concept closely related to many results related to the employee and the organization. Presenteeism, which is expressed as continuing to come to work despite different physical and mental health problems, is another concept that is thought to be related to compulsory citizenship behavior. In this direction, the study's primary purpose is to examine the relationship between compulsory citizenship behavior and presenteeism. For this purpose, the data obtained from the questions asked in the form of an online questionnaire to 374 white-collar workers in various sectors in Turkey were analyzed through the SPSS program. As a result of the findings obtained from the analysis, it was seen that there was a moderate positive and significant relationship between compulsory citizenship behaviors and presenteeism.
\end{abstract}

Key Words: Organizational Citizenship Behavior, Compulsory Citizenship Behavior, Presenteeism.

\section{Giriş}

İnsan kaynağın bir organizasyonun temel taşıdır. Personel yönetiminden insan kaynaklarına ve devamında stratejik insan kaynakları yaklaşımında giderek önem kazanan insan kaynağı, günümüz literatüründe bilhassa örgütsel davranış alanında akademik çalışmalarda üzerinde önemle durulan bir konu olarak karşımıza çıkmaktadır. İnsan kaynağının organizasyonlar için öneminin fark edilmesi ve akabinde çalışan sağlı̆̆ının üzerinde durulmaya başlanması ile birlikte presenteeism kavramı da literatürde açıklanmaya çalışılan bir kavram haline gelmiştir.

Zorunlu vatandaşlık davranışı (ZVD) ise, değiş̧en rekabet koşulları altında mücadele eden bazı organizasyonlarda çalışanlara yönelik otoriter ve zorlayıcı bir yönetim tarzının benimsemesi nedeniyle çalışanın zorunlu olarak sergilemek durumunda bırakıldığı davranışları ifade etmektedir. Zira çalışan açısından bu davranışların sergilenmesi, hem işe yönelik tatmini ve motivasyonu düşürmekte, hem de çalışlan organizasyonun verimliliğine ve performansına olumsuz yönde etki etmektedir. Bu bağlamda birbiriyle pozitif yönlü ilişkisi olduğu düşünülen bu iki kavram arasındaki ilişkinin, günümüzde yoğun iş stresi altında çalışan beyaz yakalılar üzerinde incelenmesine karar verilmiştir. 
Çalışmanın ilk bölümünde zorunlu vatandaşlık davranışı ve presenteeism kavramları ile ilgili literatür taramasına yer verilecek olup ardından araştırma hipotezi test edilerek araştırma bulguları değerlendirilmiştir. Araştırmadan elde edilen bulgular ışığında; zorunlu vatandaşlık davranışları ile presenteeism arasında pozitif yönde orta düzeyde bir ilişki olduğu tespit edilmiştir.

\section{Literatür Taraması ve Hipotez Geliştirme}

Örgütsel vatandaşlık davranışının olumsuz yönü ya da karanlık yüzü olarak tanımlanan zorunlu vatandaşlık davranışı literatürde son zamanlarda üzerinde önemle durulan bir kavram haline gelmiştir. Örgütsel vatandaşlık davranışı çalışanın örgütüne fayda sağlayabilmek adına gönüllü bir şekilde sergilediği davranışları tanımlarken, zorunlu vatandaşlık davranışı ise baskıcı ve zorlayıcı yönetim tarzı ile ortaya çıkan ve çalışanların gönüllülük esasına dayalı olarak sergilemedikleri davranışlar olarak ifade edilmektedir (Vigoda-Gadot, 2006). Olumsuz yönetim tarzının yanı sıra zorunlu vatandaşılı davranışı akran baskısı ile de ortaya çıkabilmektedir (Şeşen ve Soran, 2013; Harmancı ve Baydın, 2017). Literatürde örgütsel vatandaşlık davranışı ile zorunlu vatandaşlık davranışı arasında negatif yönde anlamlı bir ilişki olduğu, bunun yanı sıra zorunlu vatandaşlık davranışının çalışan motivasyonunu, iş tatminini ve verimliliğini düşürdüğü tespit edilmiştir (Şeşen ve Soran, 2013).

Presenteeism kavramı ise; organizasyonda bireyin, kendini rahatsız hissetmesine rağmen işe gitmeye devam etmesi şeklinde tanımlanmaktadır (Cooper, 1998; Arronsson vd., 2000; Burton vd., 2006; Hansen ve Anderson, 2008; Johns, 2010). Çalışanın hasta olmasına rağmen işe gelmesinin temel sebeplerinden birisi kariyer hedeflerine ulaşamama ve işini kaybetme

korkusudur (Koçoğlu, 2007). Bunun yanı sıra, işyükü/işs taleplerinin hızı, uzun mesai saatleri, zaman baskısı, yerine başkasının ikame edilememesi ve kaynakların yetersizliği de presenteeisme neden olabilmektedir (Arronsson ve Gustafsson, 2005). Çalışanın devamsızlık yapmadan işe gelmeye devam etmesi organizasyon için olumlu bir durummuş gibi gözükse de aslında presenteeism organizasyonlarda verimlilik, maliyet ve performans kaybına yol açmaktadır (Koopman vd., 2002; Robertson ve Cooper, 2011). Özellikle beyaz yakalı bireylerin içerisinde bulunduğu yoğun iş yükü ve iş stresinin bireylerin hem zorunlu vatandaşlık davranış1 sergilemelerine hem de presenteeisme maruz kalmalarına neden olacağı düşünülmektedir. $\mathrm{Bu}$ doğrultuda çalışmanın evreni ve örneklemi beyaz yakalılar olarak belirlenmiş ve zorunlu 
vatandaşlık davranışı ile presenteeism arasındaki ilişkinin irdelenmesine karar verilmiştir. $\mathrm{Bu}$ doğrultuda araştırmanın temel hipotezi şu şekilde oluşturulmuştur.

$H_{1}$ : Zorunlu vatandaşlık davranışı ile presenteeism arasında ilişski vardır.

\section{Araştırma}

\section{Araştırmanın Amacı ve Önemi}

Beyaz yakalıların yoğun stres altında ve aşırı iş yükü ile çalıştı̆̆ bir iş ortamında zorunlu vatandaşlık davranışı ve presenteeism gibi olumsuz sonuçlar kaçınılmazdır. $\mathrm{Bu}$ nedenle beyaz yakalılar üzerinde bu iki değişken arasındaki ilişkinin incelenmesi gerekmektedir. Bu doğrultuda araştırmanın temel amacı, zorunlu vatandaşlık davranışı ile presenteeism arasındaki ilişkinin incelenmesidir.

\section{Araştırmanın Evreni ve Örneklemi}

Araştırmanın evrenini Türkiye'de farklı sektörlerde faaliyette bulunan organizasyonlarda çalışan beyaz yakalılar oluşturmaktadır. Araştırmanın örneklemi ise bu evren içerisinden daha hızlı erişilebilir olan bireylerin örnekleme dahil edildiği kolayda örnekleme yöntemi ile çalışmaya katılan 374 katılımcıdan oluşmaktadır.

\section{Veri Toplama Araci}

Araştırmanın verileri anket yöntemi ile 01.03.2021-30.04.2021 tarihleri arasında Google forms aracıllğıyla çevrimiçi olarak toplanmıştır. Anket formu üç bölümden oluşmaktadır. İlk bölümde katılımcılarını demografik özelliklerini belirlemeye yönelik bazı sorular yöneltilmiştir. Bunlar; cinsiyet, yaş, eğitim ve kıdemdir. İkinci bölümde Vigoda-Gadot (2007) tarafından geliştirilen ve 5 ifadeden oluşan "Compulsory Citizenship Behavior Scale"in Seren ve Baydın (2017) tarafindan yapılan Türkçe'de geçerlilik ve güvenilirlik çalışması sonucu ortaya konan 5'li likert tipi “'Zorunlu Vatandaşlık Davranışı Ölçeği” kullanılmıştır. Üçüncü bölümde ise, Koopman vd. (2002) tarafından "presenteeism"in tespiti amacıyla geliştirilen "Standford Presenteeism Ölçeği" (SP-6) kullanılmıştır. Bu ölçek 6 ifadeden oluşmaktadır. 
Araştırma için katılımcılardan toplanan verilerin analizinde SPSS programı kullanılmıştır. Verilerin normallik dağılımı K-S testiyle gerçekleştirilmiştir. Ayrıca veriilerina analizinde; geçerlilik ve güvenilirlik analizleri ile korelasyon ve regresyon analizlerinden yararlanılmıştır.

\section{Araştırmanın Sınırlılıkları}

Araştırmanın temel sınırlılığı, 2020 yılının başından bu yana tüm dünyayı etkisi altına alan pandemi nedeniyle yüz yüze görüşme/anket vb. bir araştırma yapılamamış olması ve araştırmanın tamamen çevrimiçi (Google forms) yürütülmesidir.

\section{Araştırma Bulguları}

Anket formunu yanıtlayan 374 kişinin demografik özelliklerine ilişkin bilgiler Tablo 1'deki gibidir. Tablo 1'de de görüleceği üzere katılımcıların büyük bir çoğunluğunu kadınlar, 31-40 yaş aralığındaki bireyler, üniversite mezunu olanlar, eğitim sektöründe faaliyet gösteren organizasyonlarda çalışanlar, 10 yıl ve daha fazla süredir çalışma hayatında olanlar, 2 yıldan daha az aynı kurumda çalışanlar, 10 yıl ve daha fazla kıdeme sahip olanlar oluşturmaktadır. 
Tablo 1. Katılımcıların Demografik Özelliklerine İlişsin Bilgiler

\begin{tabular}{|c|c|c|c|}
\hline Değişken & Özellik & $\mathbf{F}$ & $\%$ \\
\hline \multirow[t]{3}{*}{ Cinsiyet } & Kadın & 280 & 74.9 \\
\hline & Erkek & 90 & 24.1 \\
\hline & Cevaplamayan & 4 & 1.1 \\
\hline \multirow[t]{4}{*}{ Yaş } & $20-30$ & 130 & 34.8 \\
\hline & $31-40$ & 138 & 36.9 \\
\hline & $41-50$ & 83 & 22.2 \\
\hline & 51 ve üzeri & 23 & 6.1 \\
\hline \multirow[t]{4}{*}{ Ĕgitim } & Lise & 73 & 19.5 \\
\hline & Üniversite & 230 & 61.5 \\
\hline & Yüksek Lisans & 47 & 12.6 \\
\hline & Doktora & 24 & 6.4 \\
\hline \multirow[t]{6}{*}{ Kidem } & 2 yıla kadar & 102 & 27.4 \\
\hline & 2 -4 yıla kadar & 51 & 13.6 \\
\hline & 4 - 6 yıla kadar & 43 & 11.5 \\
\hline & 6-8 yıla kadar & 36 & 9.6 \\
\hline & 8-10 yıla kadar & 30 & 8 \\
\hline & 10 y1l ve üzeri & 112 & 29.9 \\
\hline
\end{tabular}

$\mathbf{N}=374$

Tablo 2'deki Kolmogorov-Smirnov Normallik Testi verilerine bakıldığında, $-1,5<\mathrm{x}<1,5$ aras çarpıklık ve basıklık değerleri kabul edilebilir aralıkta olduğundan (Tabachnick ve Fidell, 2013) araştırmanın verilerinin normallik varsayımına uygun olduğu görülmektedir.

Tablo 2. Kolmogorov-Smirnov Normallik Testi Sonuçları

\begin{tabular}{|l|r|c|}
\hline Ölçek & Çarpıklık & \multicolumn{1}{|c|}{ Basıklık } \\
\hline Zorunlu Vatandaşlık Davranışı & .013 & -1.203 \\
\hline Presenteeism & -.268 & -.458 \\
\hline
\end{tabular}


Güvenilirlik analizi sonuçlarına bakıldığında ise Cronbach Alfa değerleri; zorunlu vatandaşlık davranışı için .919 ve presenteeism ölçeği için .763 olarak hesaplanmıştır. Faktör analizlerinde Kaiser-Meier-Olkin değerinin 0.50'in üstünde olması beklenir. Analizden elde edilen bulgular bu doğrultuda değerlendirildiğinde, ZVD ölçeği için ,832 ve presenteeism ölçeği için .682 olarak bulunan değerler istatistiksel açıdan olması gereken değerler olarak kabul görmektedir. Bartlett küresellik testi değeri ise ( $p<.001$ ) olarak bulunmuştur (Tablo 2). Bartlett küresellik testi değerinin istatistiksel açıdan yüksek anlamlılığa $(\mathrm{p}<.001)$ sahip olması ise, analiz verilerinin farklı analizler için de elverişli olduğunu, buna ek olarak analizden elde edilen verilerin faktör analizi için de uygunluk taşıdığını göstermektedir (Kalaycı vd., 2014: 322).

Tablo 2. KMO ve Barlett Küresellik Testi Sonuçları

\begin{tabular}{|l|l|l|l|}
\hline \multicolumn{2}{|l|}{} & ZVD & Presenteeism \\
\hline KMO Değeri & Ki-Kare & .832 & .682 \\
\hline \multirow{2}{*}{$\begin{array}{l}\text { Barlett } \\
\text { Küresellik Testi }\end{array}$} & df & 1472.642 & 933.058 \\
\cline { 2 - 4 } & $\mathbf{p}$ & 10 & 15 \\
\hline
\end{tabular}

Tablo 3 incelendiğinde; ZVD ölçeğinin orijinal ölçeğinde olduğu gibi tek bir faktör altında yüklendiği görülmektedir. Buna ek olarak ZVD ölçeğinde yer alan soruların toplam varyansın \%75,726’sını açıkladığı tespit edilmiştir (Tablo 4.).

Tablo 3. ZVD Ölçeği Faktör Yükleri

\begin{tabular}{|l|l|}
\hline & Faktör Yükleri \\
\hline ZVD5 & .886 \\
\hline ZVD4 & .883 \\
\hline ZVD1 & .876 \\
\hline ZVD2 & .869 \\
\hline ZVD3 & .836 \\
\hline
\end{tabular}

Ekstraksiyon Metodu: Temel Bileşenler Analizi 
Tablo 4. ZVD Ölçeği Toplam Varyansın Açıklanma Oranı

\begin{tabular}{|l|l|l|l|}
\hline Faktör & Toplam & Varyansın açıklanma oranı & Kümülatif \% \\
\hline $\mathbf{1}$ & 3.786 & 75.726 & 75.726 \\
\hline
\end{tabular}

Presenteeism ölçeğinin faktör analizi sonuçlarına bakılacak olursa; Tablo 5.'te görüleceği üzere presenteeism ölçeğinin orijinal ölçeğinde olduğu gibi tek bir faktör altında yüklendiği belirlenmiştir. Tablo 6. ise Presenteeism ölçeğinde yer alan ifadeler toplam varyansın \%45,95'ini açıklamaktadır. Ölçeğe ait ifadeler toplam varyansın 2/3'ünü açıklamakta ve tek faktörlü bir yap1 ortaya çıkmaktadır. Tek faktörlü ölçeklerde açıklanan varyansın .30 ve daha fazla olması uygun kabul edilmektedir (Büyüköztürk, 2002: 479). Presenteeism ölçeğinin de tek faktörlü bir yapıya sahip olması nedeniyle varyansın açıklama oranının kabul edilebilir düzeyde olduğu söylenebilir.

Tablo 5. Presenteeism Ölçeği Faktör Yükleri

\begin{tabular}{|l|l|}
\hline & Faktör Yükleri \\
\hline Pre2 & .767 \\
\hline Pre3 & .708 \\
\hline Pre1 & .696 \\
\hline Pre5 & .681 \\
\hline Pre4 & .613 \\
\hline Pre6 & .584 \\
\hline
\end{tabular}

Ekstraksiyon Metodu: Temel Bileşenler Analizi

Tablo 6. Presenteeism Ölçeği Toplam Varyansın Açıklanma Oranı

\begin{tabular}{|l|l|l|l|}
\hline $\begin{array}{l}\text { Faktör } \\
\text { Sayısı }\end{array}$ & Toplam & Varyansın açıklanma oranı & Kümülatif \% \\
\hline $\mathbf{1}$ & 2,757 & 45.95 & 45.95 \\
\hline
\end{tabular}

Araştırmanın temel hipotezinin sınanması amacıyla korelasyon ve regresyon analizi gerçekleştirilmiştir. Tablo 7'de görüleceği üzere zorunlu vatandaşlık davranışı ile presenteeism arasında orta düzeyde $(\mathrm{r}=.311)$ ve pozitif yönde bir ilişki olduğu görülmektedir. Bu doğrultuda araştırma hipotezi $\left(H_{1}\right)$ kabul edilmiştir. 
Tablo 7. Pearson Korelasyon Analizi Sonuçları

\begin{tabular}{|l|l|l|l|}
\hline \multicolumn{2}{|c|}{} & ZVD & Presenteeism \\
\hline ZVD & $\mathbf{r}$ & 1 & \\
\hline \multirow{2}{*}{ Presenteeism } & $\mathbf{r}$ & $.311^{* *}$ & 1 \\
\cline { 2 - 4 } & $\mathbf{p}$ & .000 & \\
\hline
\end{tabular}

Tablo 8, Tablo 9 ve Tablo 10'da ise zorunlu vatandaşlık davranışı ile presenteeism arasındaki ilişkinin tespiti amacıyla yapılan basit doğrusal regresyon analizinin sonuçlarına yer verilmiştir. Tablo11'deki model özetinde yer alan R değeri, ZVD ile presenteeism arasında ( $\mathrm{r}=.311)$ bir ilişki olduğunu, $\mathrm{R}^{2}$ değeri ise presenteeism değeri içindeki varyasyonun \%9,7sinin ZVD değişkenine atfedilebileceğini göstermektedir.

Tablo 8. Model Özeti

\begin{tabular}{|l|l|l|l|l|}
\hline Model & $\mathbf{r}$ & $\mathbf{r}^{\mathbf{2}}$ & Düzeltilmiş $^{\mathbf{2}}$ & Tahminin Standart Hatası \\
\hline 1 & $.311^{\mathrm{a}}$ & .097 &, 095 &, 92916 \\
\hline
\end{tabular}

a. Tahmin ediciler: (Sabit), ZVD

Tablo 9'da yer alan ANOVA a tablosu modelin anlamlı olup olmadığını göstermektedir. Tabloda da görüleceği üzere $F$ ve $p$ değerlerine göre model $(p<.001)$ anlamlıdır. ZVD değişkeni presenteeism değişkeninin anlamlı bir tahmin edicisidir.

Tablo 9. ANOVA Tablosu

\begin{tabular}{|l|l|l|l|l|l|}
\hline Model 1 & Kareler Toplamı & df & Ortalama Kare & F & p \\
\hline Regresyon & 34.494 & 1 & 34.494 & 39.953 & .000 \\
\hline Artık & 321.65 & 372 & .863 & & \\
\hline Toplam & 355.658 & 373 & & & \\
\hline
\end{tabular}

a. Bağımlı Değişken: Presenteeism

b. Tahmin ediciler: (Sabit), ZVD

Tablo 10'da görüleceği üzere zorunlu vatandaşlık davranışı ile presenteeism arasındaki ilişkide; her bir zorunlu vatandaşlık davranışı presenteeismi. 232 artırmaktadır. Bu doğrultuda zorunlu 
vatandaşlık davranışı ile presenteeism arasındaki ilişki için basit doğrusal regresyon formülü: presenteeism $=2.418+.232 * Z V D$ olarak ifade edilmektedir.

Tablo 10. Katsayılar Tablosu

\begin{tabular}{|l|l|l|l|l|l|}
\hline Model 1 & $\begin{array}{l}\text { Std. Edilmemiş } \\
\text { Beta }\end{array}$ & $\begin{array}{l}\text { Katsayıların } \\
\text { Standart Hatası }\end{array}$ & $\begin{array}{l}\text { Std. Edilmiş } \\
\text { Beta }\end{array}$ & $\mathbf{t}$ & $\mathbf{p}$ \\
\hline (Sabit) & 2.418 & .118 & & 20.553 & .000 \\
\hline ZVD & .232 & .037 & .311 & 6.321 & .000 \\
\hline
\end{tabular}

a. Bağımlı Değişken: Presenteeism

\section{Sonuç ve Öneriler}

Her geçen gün değişen zorlu rekabet koşulları altında sürdürülebilir bir rekabetçi avantaj elde etmeye çalışan organizasyonlar, kendileri için altın değerinde olan insan kaynağını en etkin ve verimli şekilde yönlendirmeye çalışmaktadırlar. $\mathrm{Bu}$ sayede organizasyonun verimliliğini, performansını ve karlılığını artırmaya çabalamaktadırlar. Bu amaçla organizasyonlar, insan kaynağına titizle önem vermekte, çalışan memnuniyetini ve performansını artırmaya yönelik pek çok faaliyette bulunmaktadırlar.

Örgütsel vatandaşlık davranışı olarak kavramsallaştııılan ve çalışan tarafından mevcut iş tanımının dışında gönüllü olarak sergilenen ekstra rol davranışlarının karşıtı olarak zorunlu vatandaşlık davranışı karşımıza çıkmaktadır. Bu davranış, organizasyonlardaki otoriter ve zorlayıcı yönetim tarzı nedeniyle çalışanların gönüllülük esasına dayanmadan, kimi zaman işini kaybetme korkusuyla veya başka pek çok nedenle sergilemek durumunda kaldığı davranışları ifade etmektedir. Bunun yanı sıra çalışanlar için olumsuz sonuçlar doğuran bir diğer kavram olan presenteeism ise çalışanların fiziki veya ruhsal sağlı problemleri olmasına rağmen işe gelmeye devam etmeleri şeklinde tanımlanmaktadır.

Her iki kavramın da hem organizasyona hem de çalışana olumsuz sonuçlar doğurduğu bilinmektedir. Bilhassa yoğun iş stresi ve iş yükü altında çalışan beyaz yakalılar her iki durumdan da oldukça etkilenmektedirler. Bu doğrultuda araştırmamızda zorunlu vatandaşlık davranışı ile presenteeism arasındaki ilişki beyaz yakalılar üzerinde incelenmiştir. Araştırmadan elde edilen 
bulgular neticesinde, zorunlu vatandaşlık davranışı ile presenteeism değişkenlerinin birbirini destekleyen bir yapıyı ortaya koydukları görülmektedir.

Araştırmanın literatüre zorunlu vatandaşlık davranışı ve presenteeism arasındaki ilişkiyi inceleyen araştırma sayısının azlığı nedeniyle katkı sağlayacağı düşünülmektedir. Sonraki çalışmalara yönelik olarak; zorunlu vatandaşlık davranışı ile presenteeism arasındaki ilişkinin farklı sektörlerde karşılaştırmalı olarak incelenmesini, bu ilişkide düzenleyici veya aracı etkisi olabileceği düşünülen değişkenlerin modele dahil edilmesi önerilebilir.

\section{Kaynakça}

Arronsson, G., Gustafsson, K. Ve Dallner, M. (2000). "Sick but yet work: An Empirical Study of Sickness Presenteeism”, Journal of Epidemology and Community Health, 54: 502-509. Arronsson, G. ve Gustafsson, K. (2005). "Sickness Presenteeism: Prevalance, Attendance-pressure Factors, and an Outline of a Model for Research", Journal of Occupational and Environmental Medicine, 47: 958-966.

Burton, W.N., Chen, C-Y., Conti, D.J., Schultz, A.B. ve Edington, D.W. (2006). “The Association between Health Risk Change and Presenteeism Change", Journal of Occupational and Environmental Medicine, 48: 252-263.

Büyüköztürk, Ş. 2002. Faktör Analizi: Temel Kavramlar ve Ölçek Geliştirmede Kullanımı, Kuram ve Uygulamada Eğitim Yönetimi, 32: 470-483.

Cooper, Carry L. (1998). “The Changing Nature of Work”, Community Work and Family, 1(3): 313-317.

Johns, G. (2010). "Presenteeism in the Workplace: A Review and Research Agenda", Journal of Organizational Behavior, 31: 519-542.

Hansen, C.D. ve Anderson, J.H. (2008). "Going ill to Work: What Personel Circumstances,Attitudes and Work-related Factors are Associated with Sickness Presenteeism”, Social Science and Medicine, 67(6): 956-964.

Harmancı Seren A.K. ve Ünaldı Baydın, N. (2017). "Zorunlu Vatandaşlık Davranışı Ölçeğinin Türkçe'de Geçerlik ve Güvenilirlik Çalışması: Hemşireler Üzerinde Bir Araştırma”, Sağlık ve Hemşirelik Yönetimi Dergisi, 4(2): 43-49. 
Kalaycı, Ş. vd 2014. SPSS Uygulamalı Çok Değişkenli İstatistik Teknikleri, 6. Baskı, Ankara: Asil Yayın Dağıtım.

Koçoğlu, M. (2007). İşletmelerde Presenteeism Sorunu ve İnsan Kaynakları Yönetimi Çerçevesinde Mücadele Yöntemleri, Yüksek Lisans Tezi, Yıldız Teknik Üniversitesi, Sosyal Bilimler Enstitüsü, İstanbul.

Koopman, C., Kenneth R. Pelletier, James F. Murray, C.E. Sharda, Marc L. Berger, Turpin R.S., Hackleman P., Gibson, P., Holmes, D.M., Bendel, T. (2002). "Standford Presenteeism Scale: Health Status and Employee Productivity, Journal of Occupational and Environmental Medicine, 44: 1-12.

Robertson, I. ve Cooper, C.L. (2011). Well-being: Productivity and Happiness at Work, Hampshire, UK: Palgrave Macmillan.

Şeşen, H. ve Soran, S. (2013). “Örgütsel Vatandaşl1ktan Zorunlu Vatandaşlı̆̆a: Zorunlu Vatandaşlık Davranışının Bazı Faktörlerle İlişkisi”, 21. Ulusal Yönetim ve Organizasyon Kongresi Bildiri Kitabı, Kitahya, 407-410.

Vigoda-Gadot, E. (2006). "Compulsory Citizenship Behavior: Theorizing some Dark Sides of the Good Soldier Syndrome in Organizations”, Journal for Theory of Social Behavior, 36(1): 77-93.

Vigoda-Gadot, E. (2007). "Redrawing the boundaries of OCB? An empirical examination of compulsory extra-role behavior in the workplace". Journal of Business and Psychology, 21(3), 377-405. 